\title{
USOS E ABUSOS DO TERRITÓRIO, PAISAGEM E PROBLEMAS ESPACIAIS RELACIONADOS AO PROCESSO DE SALINIZAÇÃO DO BAIXO SÃO FRANCISCO
}

\author{
Agnes de França Dantas Serrano ${ }^{1}$
}

Resumo: O presente trabalho tem como objetivo refletir acerca de alguns dos problemas socioespaciais relacionados ao processo de salinização do Baixo São Francisco por meio da análise da transformação da paisagem e do conceito de uso do território. Considera a apropriação dos recursos hídricos do rio para a instalação de hidrelétricas a fim de gerar energia e para o desenvolvimento da agricultura como usos que provocaram a salinização do Baixo São Francisco, que tem como uma de suas consequências o desaparecimento da antiga vila do Povoado Cabeço, no litoral do estado de Sergipe. Este artigo se propôs a dar luz a algumas das questões enfrentadas em âmbito espacial a partir das ações que têm provocado a salinização do rio e aos desdobramentos dela decorrentes, e, a partir de suas reflexões, fortalecer o chamado para os olhares e pesquisas geográficas sobre a temática discutida.

Palavras-chave: Usos do Território; Salinização; Rio São Francisco; Paisagem; Processos Espaciais.

\section{USES AND ABUSES OF THE TERRITORY, LANDSCAPE, AND SPATIAL PROBLEMS RELATED TO THE SÃO FRANCISCO SALINIZATION PROCESS}

\begin{abstract}
This paper aims to reflect about social and spatial problems related to São Francisco lower course salinization process, which will be done by the analysis of the landscape transformation and the concept of the use of territory. It considers the appropriation of the water resources of the river for the installation of hydroelectric dams in order to generate energy and for agriculture as uses that caused the salinization of the Lower San Francisco, and one of its consequences is the disappearance of the old village of Povoado Cabeço, on the coast of the state of Sergipe. This article's propose is to give light to some of the spatial problems and the actions that resulted in the salinization of the river and, from its reflections, to strengthen the call for the looks and geographic surveys on the subject matter discussed.
\end{abstract}

Keywords: Uses of the Territory; Salinization; São Francisco River; Landscape, Spatial Processes.

\footnotetext{
${ }^{1}$ Docente da Secretaria de Educação do Distrito Federal. agnes.serrano@gmail.com Estudos Geográficos, Rio Claro, 17(1): 32-42, jan./jun. 2019 (ISSN 1678-698X) http://www.periodicos.rc.biblioteca.unesp.br/index.php/estgeo 


\section{INTRODUÇÃO}

O processo de formação do território brasileiro e sua atual configuração estão intrinsecamente relacionados às localizações e usos dos recursos hídricos do Brasil, e um dos principais rios a influenciar nas dinâmicas espaciais do país é o São Francisco. Conhecido como o Rio da Integração Nacional, dada sua importância e dimensão, o São Francisco nasce na Serra da Canastra, no estado de Minas Gerais, e deságua no litoral da região Nordeste, apresentando uma extensão superior a $2.800 \mathrm{~km}$. É o principal curso d'água de uma das mais significativas bacias hidrográficas do país - que leva o nome do próprio rio -, a qual atravessa os estados de Minas Gerais, Bahia, Pernambuco, Sergipe, Alagoas e Goiás, além do Distrito Federal, e ocupa uma região que envolve cerca de $10 \%$ dos municípios brasileiros.

Além das cidades que cresceram às suas margens, o rio São Francisco também tornou possível o desenvolvimento de diversas atividades econômicas ao longo do tempo, das quais é possível citar, por exemplo, a pesca, a irrigação de áreas destinadas à agricultura e a geração de energia. Com respeito a esta última, destaca-se que a bacia hidrográfica do São Francisco abriga, dentre outras de menor dimensão, seis grandes usinas hidrelétricas - Xingó, Paulo Afonso, Itaparica, Sobradinho, Três Marias e Moxotó -, voltadas, principalmente, ao abastecimento energético da população nordestina.

A prosperidade regional viabilizada pelas águas do rio não se limita aos aspectos econômicos. A relação da população com o "Velho Chico", como é popularmente chamado, também proporcionou o surgimento de ricas manifestações da cultura brasileira, lendas, histórias, tradições e festejos que ainda se mantém vivos com o passar de gerações.

Toda a dinâmica social que, historicamente, constitui a espacialidade do rio São Francisco por meio de técnicas diversas e a relevância da bacia hidrográfica deste rio para a economia do país fizeram surgir, ao longo do tempo, conflitos de interesses inúmeros e questões de ordem social e política que têm sido debatidos e estudados por décadas no Brasil, dada sua complexidade. Um dos temas mais polêmicos que há anos envolve a destinação e a utilização dos recursos hídricos do São Francisco é a transposição de suas águas, que teria por justificativa o discurso da necessidade de promoção do abastecimento de parte da população do semiárido nordestino mais desprovida de recursos hídricos, bem como de produtores agrícolas. Mas a transposição não é o único tema controverso quando se trata das águas do São Francisco. A implantação de suas seis principais hidrelétricas e as implicações destes processos ainda permanecem sendo alvos de extenso debate haja vista seus consequentes impactos socioambientais - e estudos, assim como o desmatamento das margens do rio, o avanço do desenvolvimento urbano, os efeitos da atividade turística, ou mesmo a ocupação do solo na região de abrangência de sua bacia.

Recentemente, outra temática começou a ganhar destaque midiático e a requerer maiores estudos com relação às suas causas e consequências. Ela diz respeito a um grave e real problema que passou a ser percebido no Baixo São Francisco, principalmente, e cujos efeitos já são sentidos pela população e pela biodiversidade regional: o processo de salinização, caracterizado pela elevação dos níveis de salinidade do rio devido à intensa diminuição de sua vazão e ao avanço do mar sobre seu leito. De acordo com Rossi (2017), em publicação realizada pelo

Estudos Geográficos, Rio Claro, 17(1): 32-42, jan./jun. 2019 (ISSN 1678-698X) http://www.periodicos.rc.biblioteca.unesp.br/index.php/estgeo 
jornal El País, este problema vem sendo causado não apenas por questões relativas ao clima, em si, mas por problemas administrativos que têm durado décadas.

É principalmente entre os municípios de Piaçabuçu, no estado de Alagoas, e Brejo Grande, em Sergipe - região de abrangência da Área de Proteção Ambiental da Foz do São Francisco -, que as transformações e as consequências da salinização já são percebidas mais intensamente. Mas seus desdobramentos não se restringem apenas a estes municípios, tampouco é correto afirmar que se originou da escala local o desencadear do processo de salinização do baixo rio e seu agravamento. A instalação das hidrelétricas ao longo de todo o rio é considerada um dos principais fatores a desencadear a redução de sua vazão e permitir que o mar avance curso d'água adentro, prejudicando a qualidade do abastecimento à população, a vida e a biodiversidade regional. O uso agrícola do território também se constitui como outro fator que promove a redução da vazão do rio, haja vista a utilização dos recursos hídricos do São Francisco para a agricultura irrigada, atividade desenvolvida ao longo de suas margens. Deste modo, deduz-se que problemas presentes na desembocadura do rio refletem ações relativas aos usos dos recursos hídricos de toda a bacia hidrográfica do São Francisco.

Para além de entender a salinização no São Francisco e os desdobramentos dela decorrentes em seus aspectos meramente técnicos ou físicos, cabe adensar também a discussão com enfoque geográfico sobre como o espaço socialmente produzido vem sendo afetado por este processo, como proposto na presente pesquisa. $O$ ambiente muda, o social sofre transformações, o cotidiano se ressignifica, costumes e tradições passam por adaptações a partir da interferência humana no rio para fins econômicos, e a análise do espaço, por meio de suas categorias, revela tais processos e suas implicações.

Com base neste cenário, o objetivo deste trabalho é refletir acerca de alguns dos problemas socioespaciais relacionados ao processo de salinização do baixo São Francisco por meio da análise da transformação da paisagem e do conceito de uso do território a partir da apropriação dos recursos hídricos do rio especialmente para a geração de energia elétrica e para a produção agrícola. A análise realizada terá como referência o caso do desaparecimento da antiga vila do Povoado Cabeço - SE e o processo de desterritorialização de sua população.

Para o desenvolvimento da presente pesquisa, optou-se metodologicamente pelo levantamento bibliográfico a fim de dialogar com outros autores acerca da temática debatida, bem como embasar teoricamente o estudo. Além disso, realizouse um primeiro trabalho de campo, responsável pelo próprio início desta investigação. A busca de imagens capazes de exemplificar os problemas e o tema debatidos e a elaboração de mapa para indicar a localização da antiga vila do Povoado Cabeço também foram recursos metodológicos aos quais se recorreu.

\section{USOS E ABUSOS DO TERRITÓRIO E A SALINIZAÇÃO COMO CONSEQUÊNCIA}

O interesse pela temática dos efeitos espaciais gerados pelo processo de salinização no baixo São Francisco surgiu principalmente a partir da verificação in loco de que a paisagem na foz deste rio, localizada entre os estados de Sergipe e Alagoas, sofreu intensa transformação nas últimas décadas. A constatação da comunidade local sobre o avanço do mar e o consequente desaparecimento de construções, povoados, bem como as mudanças no cotidiano da população

Estudos Geográficos, Rio Claro, 17(1): 32-42, jan./jun. 2019 (ISSN 1678-698X) http://www.periodicos.rc.biblioteca.unesp.br/index.php/estgeo 
ribeirinha do baixo rio, aguçaram a curiosidade de se verificar os porquês e os processos que podem ter provocado tantas transformações, o que levou, em julho de 2016, ao início desta pesquisa, por meio de conversas informais junto a moradores locais e observações em campo. A partir de então, percebeu-se a necessidade de se analisar, à luz do pensamento geográfico e ainda que brevemente, alguns dos efeitos espaciais da salinização de um dos principais cursos d'água do Brasil.

Entender a salinização como um processo complexo e como resultado de ações regionais, não locais, é compreendê-la como decorrência da utilização do potencial hídrico do São Francisco para fins específicos, caracterizados como usos do território. A este respeito, compreende-se que o conceito de "território usado" está intrinsecamente relacionado ao de espaço geográfico, podendo ser considerado seu sinônimo, conforme Santos (1994). Os usos do território podem ser assim definidos:

[...] não só pela implantação de infraestruturas, para as quais estamos igualmente utilizando a denominação sistemas de engenharia, mas também pelo dinamismo da economia e da sociedade. São os movimentos da população, a distribuição da agricultura, da indústria e dos serviços, o arcabouço normativo, incluídas a legislação civil, fiscal e financeira, que, juntamente com 0 alcance e a extensão da cidadania, configuram as funções do novo espaço geográfico. (SANTOS e SILVEIRA, 2011, p. 19).

Santos e Silveira acrescentam ainda que, ao se definir um território, é necessário que se considere a materialidade e a imaterialidade inseparáveis que o envolvem, ou seja, "a natureza e seu uso, que inclui a ação humana, isto é, trabalho e política. Desta maneira, defrontamo-nos com o território vivo, vivendo" (SANTOS E SILVEIRA, 2011, p. 225). Ou seja, as ações políticas, sociais, culturais e econômicas se realizam no território e ocorrem por conta de interesses conflitantes relacionados aos diversos e possíveis usos que nele podem se realizar.

Portanto, é possível afirmar que a produção de energia elétrica e a agricultura são exemplos de como o território pode ser usado. Especificamente para o desenvolvimento destes dois usos, muito se tem aproveitado do potencial hidrelétrico do Rio São Francisco ao longo do tempo, e a este aproveitamento é atribuída à ocorrência de impactos em toda a extensão do referido curso d'água. Com base em Fontes (2011), Araújo, Aguiar Netto e Gomes esclarecem que:

[...] estes usos são responsáveis por alterações significativas em seu regime hidrológico [do São Francisco], refletindo com maior radicalidade na região do baixo curso, promovendo assoreamento do leito, erosão das margens, redução da fauna e da flora, aumento da cunha marítima e salinização da água e do solo, aumento do espelho e redução da lâmina d'água (ARAÚJO, AGUIAR NETTO e GOMES, 2016, p. 240).

Considerando que a instalação de hidrelétricas ao longo do curso d'água, como forma de uso do território por meio da apropriação dos recursos hídricos para geração de energia, representa uma das principais causas atribuídas pela população que vive cotidianamente o local à redução da vazão do São Francisco e à consequente salinização de sua foz, Souza salienta que:

Estudos Geográficos, Rio Claro, 17(1): 32-42, jan./jun. $2019 \quad$ (ISSN 1678-698X) http://www.periodicos.rc.biblioteca.unesp.br/index.php/estgeo 
As modificações no padrão de descarga do rio devido à regularização da vazão pelas barragens na região à montante da sua foz têm ocasionado alterações nas condições hidrodinâmicas reinantes no estuário do rio São Francisco. Tais mudanças refletem na circulação interna das correntes e grau de mistura através da maior presença de águas costeiras penetrando no canal principal do rio (SOUZA, 2015, p. 16).

O autor complementa, afirmando que não apenas a biodiversidade é afetada com as consequências da salinização, mas também a população local, em primeira escala, a qual passa a ser impedida de prosseguir usando o território como o fazia:

Tendo em vista que a principal fonte de renda da população ribeirinha é a pesca, a população vem sendo diretamente afetada pela redução da produção pesqueira. Esta redução foi ocasionada pelo controle da vazão do rio, eliminando o ciclo anual de enchentes no baixo São Francisco (SOUZA, 2015, p. 17).

É necessário, portanto, entender a (re)produção do espaço, ao longo do tempo, por meio do uso do território para fins específicos, defendidos por agentes cujos interesses econômicos, ainda que implícitos, podem gerar efeitos sociais e ambientais irreversíveis. Deste modo, a sessão a seguir discute sobre efeitos espaciais, em si, do avanço do mar sobre o São Francisco e a transformação paisagística que a salinização do rio já provocou em sua foz.

\section{APROPRIAÇÃO PRIVADA DOS RECURSOS HÍDRICOS E DESTERRITORIALIZAÇÃO: O CASO DO POVOADO CABEÇO - SE}

São poucas as pesquisas que já começam a surgir envolvendo o tema da salinização, especificamente, com relação ao Rio São Francisco. É o caso dos próprios esforços analíticos realizados por Souza (2015) e do estudo do Programa de Monitoramento da Cunha Salina, efetivado em 2005 pelo Ministério da Integração Nacional (BRASIL, 2005). Entretanto, as tímidas investigações que, de algum modo, abordaram as transformações espaciais da região da foz do São Francisco a partir dos problemas do rio se limitaram, em geral, a tratar de aspectos predominantemente técnicos. Acredita-se que as pesquisas sobre a salinização não podem restringir olhares a estas questões. Daí a relevância dos estudos geográficos, que não limitam suas análises à salinização no rio, por si só, como um fenômeno físico isolado. Entender a totalidade do processo de salinização, do ponto de vista geográfico, requer também a realização de um olhar para as vivências cotidianas e para o planejamento político e econômico realizado acerca do espaço em que estas vivências se realizam.

Supõe-se que o uso indiscriminado dos recursos hídricos do São Francisco - que historicamente gerou problemas de ordem social, natural e, portanto, espacial - devem-se à própria transformação das águas do rio em mercadoria por meio de sua apropriação privada. A utilização dos recursos do rio para a produção agrícola e geração de energia são considerados por Cruz um modo de se privatizar a água no Brasil. Segundo a autora:

Estudos Geográficos, Rio Claro, 17(1): 32-42, jan./jun. $2019 \quad$ (ISSN 1678-698X) http://www.periodicos.rc.biblioteca.unesp.br/index.php/estgeo 
[...] a privatização não ocorre somente pelo fornecimento de água e saneamento. [...] especialmente no Brasil, a privatização ocorre pela construção de barragens e hidrelétricas, pela irrigação no agronegócio, pela carcinicultura, pela transposição de rios para canais e reservatórios, toda ela destinada aos interesses de empresas multinacionais (CRUZ, 2010, p. 48).

Os vários problemas que o Baixo São Francisco vem sofrendo, como a própria salinização, seus agravamentos e demais consequências socioespaciais e ambientais causadas pelo uso indiscriminado de suas águas, a complexidade na gestão dos recursos hídricos e a transformação destes recursos em mercadoria já leva pesquisadores a afirmar que há a possibilidade de o rio não conseguir se restabelecer. De acordo com Unger (2001, p. 171), se não houver profundas mudanças no planejamento e ações do modelo econômico de desenvolvimento do país, o São Francisco, em breve, poderá se transformar em um rio temporário. Nas palavras da autora, o rio "encontra-se numa situação limite, pois a previsão é de que, se não houver uma mudança radical nas causas de sua degradação, a bacia do São Francisco poderá se transformar num 'deserto irrecuperável'” (UNGER, 2001, p. 171). Ainda de acordo com Unger, as políticas públicas voltadas para a referida bacia hidrográfica têm sido desenvolvidas em função da expansão do capital, e não do atendimento aos interesses reais da população local:

Historicamente excluídos das políticas públicas, os pobres do São Francisco são hoje vítimas do investimento de bilhões de dólares do dinheiro público em projetos que destroem a base de sua sobrevivência. Rio e povo são uma mesma e única vida ameaçada pela exploração irracional e criminosa de suas riquezas (UNGER, 2001, p. 173).

É com base em toda essa discussão que se propõe a inserção do olhar crítico e geográfico no estudo da referida problemática. A contribuição que as categorias de análise espaciais, a exemplo da paisagem, podem trazer ao debate evidenciam os efeitos temporais da execução de planejamentos limitados, incompletos, ineficientes, excludentes, mas efetivados territorialmente, ainda que tenham priorizado o econômico, e não o social e o cultural, o privado, e não o coletivo, como será discutido a seguir.

\section{A ESPACIALIDADE RIBEIRINHA E O DESAPARECIMENTO DA ANTIGA VILA DO POVOADO CABEÇO}

A transformação da paisagem no baixo rio ao longo do tempo e suas consequências vem revelando os efeitos dos conflitos de interesse em relação ao uso do território, em especial, àqueles ligados aos recursos hídricos do São Francisco. Por ser reveladora, a paisagem é, ao mesmo tempo, dimensão visível e representação do espaço. Para Sauer,

Não podemos formar uma ideia de paisagem a não ser em termos de suas relações associadas ao tempo, bem como suas relações vinculadas com o espaço. Ela está em um processo constante de desenvolvimento ou dissolução e substituição. Assim, no sentido corológico, a alteração da área modificada pelo homem e sua

Estudos Geográficos, Rio Claro, 17(1): 32-42, jan./jun. 2019 (ISSN 1678-698X) http://www.periodicos.rc.biblioteca.unesp.br/index.php/estgeo 
apropriação para o uso são de importância fundamental (SAUER, 1998, p. 42).

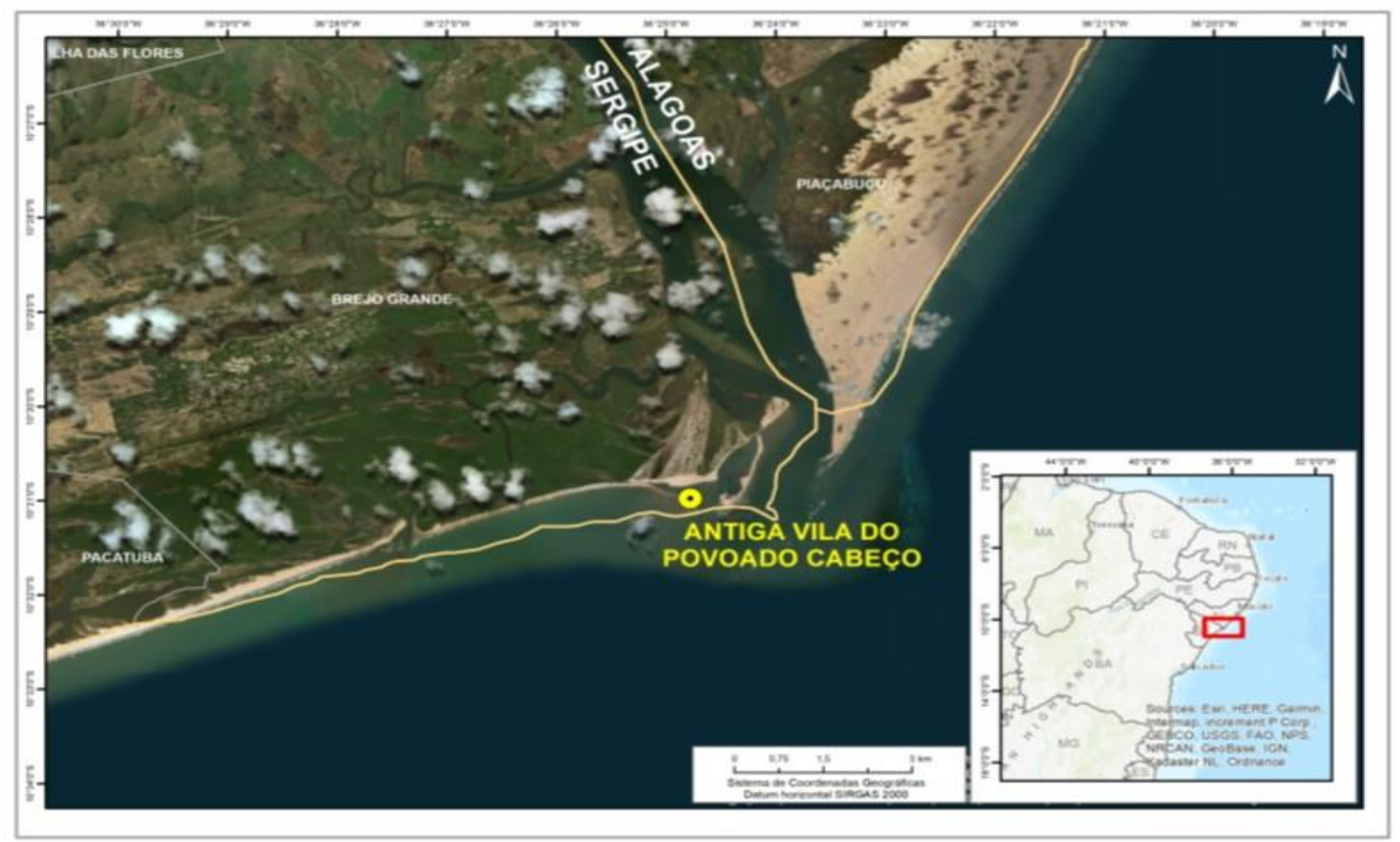

Figura 1 - Localização da Antiga Vila do Povoado Cabeço - SE

Org.: SERRANO, Agnes.

Autoria: FREITAS, Brisly.

Fonte: IBGE, 2017.

Foi a observação da gradativa transformação da paisagem na foz do São Francisco que primeiro denunciou à população local os efeitos de prováveis equívocos no planejamento e/ou regulação e execução de ações relativas aos usos dos recursos hídricos do rio, ocasionando a consequente diminuição de sua vazão e o aumento da salinidade de suas águas.

Ainda na década de 1990, o avanço do mar sobre o São Francisco provocou o desaparecimento da antiga vila do Povoado Cabeço, que se localizava no extremo leste litorâneo do município de Brejo Grande, no estado de Sergipe, como identificado na Figura 1. A população local atribui este sumiço à redução da vazão do rio ao longo do tempo, o que permitiu o consequente avanço do mar sobre as casas e demais construções daquela comunidade e forçou a fuga populacional para outras localidades. Dentre as principais causas notadas e citadas e pelos morados da diminuição do fluxo de água do São Francisco está a instalação de diversas hidrelétricas ao longo do curso de todo o rio.

Atualmente, tramita na $2^{\text {a }}$ vara do Tribunal Superior Federal 5 uma ação civil pública $^{2}$ contra a Companhia Hidroelétrica do São Francisco- CHESF. O processo atribui o desaparecimento da vila do povoado Cabeço justamente à diminuição da vazão do rio, provocada, especificamente, desde a instalação da Hidrelétrica de Xingó $^{3}$. De acordo com os dados do próprio processo, a CHESF nega

\footnotetext{
${ }^{2}$ Processo ${ }^{\circ}$ 0002809-27.2002.4.05.8500.

${ }^{3}$ Inaugurada em 1994.

Estudos Geográficos, Rio Claro, 17(1): 32-42, jan./jun. $2019 \quad$ (ISSN 1678-698X) http://www.periodicos.rc.biblioteca.unesp.br/index.php/estgeo
} 
responsabilização em quaisquer causas associadas ao desaparecimento da antiga vila do município de Brejo Grande. Entretanto, há autores que indicam que a implantação da barragem foi uma das principais responsáveis pelas transformações sofridas no modo de vida da população local:

As consequências dos impactos na calha do baixo São Francisco são sentidas a partir do início das obras de Xingó, na década de 1980. A partir do ano de 1994, após a entrada em operação da primeira turbina da usina, a erosão marinha no povoado Cabeço se acelera, com perdas materiais para os moradores. No ano de 2001, a invasão do povoado [pelo mar] foi total, desterrando a comunidade, que ficou desamparada, nem mesmo sendo compensada pela CHESF (ARAÚJO, AGUIAR NETTO e GOMES, 2016, p. 241).

A abertura de uma ação civil pública exemplifica o sentimento de pertencimento e identificação que a comunidade ainda possui com relação à antiga vila, hoje submersa, bem como sua indignação com o descaso do poder público em relação às memórias coletivas locais. O processo de desterritorialização daquela comunidade, contudo, não desapareceu em meio às águas salgadas, mas está marcado tanto no imaginário coletivo quanto evidenciado na transformação da paisagem local.

A alteração paisagística da região onde se localizava este povoado, exemplificada por meio de registros fotográficos, já demonstra quão profundas têm sido as transformações que o avanço do mar sobre o baixo rio vem provocando ao longo do tempo. A figura 2 retrata justamente as mudanças ocasionadas a partir do avanço do mar sobre a localização do antigo povoado e o consequente desaparecimento desta vila. A referência para analisar a intensidade deste processo é o farol da antiga vila, ainda considerado um dos pontos turísticos da foz do São Francisco, mesmo que, atualmente, localizado dentro do mar.

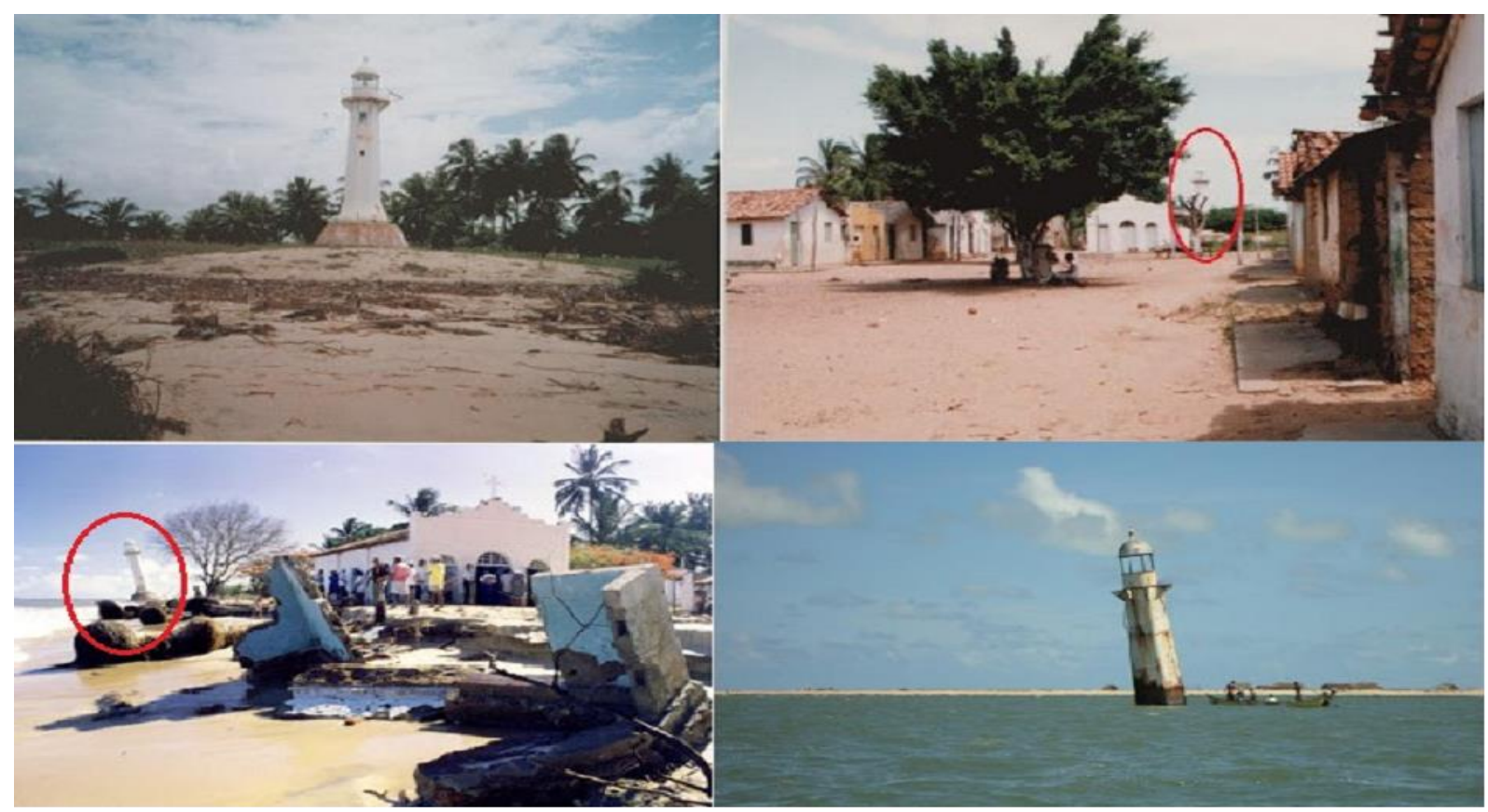

Figura 2 - Povoado cabeço: décadas de 1980, 1990, 2000 e 2013, respectivamente, tendo como referência o antigo farol da vila.

Fonte: http://antoniogeografo.blogspot.com.br. Acesso em 12 de abril de 2018.

Estudos Geográficos, Rio Claro, 17(1): 32-42, jan./jun. 2019 (ISSN 1678-698X) http://www.periodicos.rc.biblioteca.unesp.br/index.php/estgeo 
Para Besse (2010), a paisagem pode ser considerada uma parte do "estar no mundo" de um grupo, forma sua identidade coletiva, o que implica analisá-la apenas a partir do envolvimento daqueles que a construíram e pela qual se sentem envolvidos. Para o autor, esta identificação com a paisagem pode ser considerada a necessidade do próprio reconhecimento de determinado grupo. O desaparecimento da antiga vila do povoado Cabeço e a revolta com o fato evidenciam também esta submersão do ser coletivo em seu território, bem como sua impossível dissociação. A respeito disso, Besse complementa, afirmando:

Pero entonces, si el paisaje corresponde a nuestra implicacion en el mundo, eso quiere decir que no está lejos de nosotros, em el horizonte, sino que, por el contrario, nos resulta cercano, estamos em contacto com él, digamos que nos envuelve. Podría decirse, inclusive, que esse contacto esse conjunto de contatos com el mundo circundante, o sea esa experiência física, son los que hacen el paisaje. El paisaje es um espacio táctil, antes que óptico (BESSE, 2010, p. 5).

Entender o sentimento de impotência de quem se viu obrigado a sair da área invadida pelo mar é corroborar novamente com Besse, quando o autor afirma que:

El paisaje cuenta la historia de aquellos que viveron en él. El paisaje es una obra y en tanto tal, es portador de sentido. Es la expressión de una relación, la de los hombres y la superficie terrestre, en la que se constituye el espacio proprio de la geograficidad (BESSE, 2010, p. 9).

Portanto, olhar a evolução paisagística, enxergar o resultado das ações humanas sobre o espaço e ver-se desterritorializado é perceber-se sem parte de sua história, daquilo que imprimi sentido ao próprio existir e fazer cotidianos.

Também com base no conceito de lugar, criado a partir da relação dos sujeitos com o espaço em que vivem e se identificam, é possível analisar a questão do desaparecimento da vila e o sentimento de desterritorialização provocado em seu povo a partir do que afirma Tuan (1983), para quem os homens, enquanto produtores de símbolos apegam-se a lugares por meio de suas experiências, dos sentimentos e das emoções que delas emanam.

Entretanto, entender este processo de redefinição de sentidos e ressignificação espacial, em suas mais variadas frações e categorias de análise, é também compreender que o avanço do mar e a inevitável salinização do baixo rio devem ser analisados como consequência de usos e abusos do território por meio da inadequada utilização e gestão dos recursos hídricos não em escala local, mas ao longo de todo o curso d'água em questão.

É objetivando compreender melhor e encontrar soluções para os problemas já enfrentados com o agravamento da salinização do baixo São Francisco que se propõe o desenvolvimento de mais pesquisas capazes de englobar o social, o espacial e o ambiental para investigar a problemática em questão, e não os tomar como partes isoladas de um sistema no qual se apresentam indissociáveis. Por certo, a salinização do São Francisco e seus efeitos não são questões de ordem meramente ambiental, e cabe justamente à geografia o desafio de estudar a problemática para além de seus aspectos físicos e analisá-la em toda sua complexidade espacial.

Estudos Geográficos, Rio Claro, 17(1): 32-42, jan./jun. $2019 \quad$ (ISSN 1678-698X) http://www.periodicos.rc.biblioteca.unesp.br/index.php/estgeo 


\section{CONSIDERAÇÕES FINAIS}

Considera-se desafiador dedicar-se à compreensão das contradições de nossa sociedade, em especial, quando se trata de investigar questões relativas aos aspectos sociais, ambientais, econômicos, políticos, espaciais e, portanto, geográficos relacionados a uma das principais bacias hidrográficas do país.

É Reconhecido que há uma vasta legislação que diz respeito à preservação dos elementos naturais e culturais relativos à área em estudo, como as margens de rios e seus recursos hídricos. Entretanto, o próprio surgimento do processo de salinização e suas consequências espaciais já evidentes, como o desaparecimento da antiga vila do Povoado Cabeço e a necessidade de reterritorialização de sua comunidade em outro local, sinalizam que a legislação não tem se mostrado eficiente e/ou suficiente no que se refere à garantia da manutenção da qualidade das águas do São Francisco e dos costumes e tradições que giram em torno destas águas. Por estes mesmos aspectos, considera-se que o planejamento estatal tem falhado no que se refere ao respeito e reconhecimento da complexidade social e cultural da realidade espacial ribeirinha, em sua totalidade, principalmente em se tratando da priorização da produção de energia por meio da instalação das hidrelétricas no São Francisco.

Este trabalho não teve o intuito de indicar soluções ou caminhos a serem percorridos nas resoluções dos problemas discutidos em seu desenvolvimento, mas se propôs a dar luz a algumas das questões enfrentadas em âmbito espacial a partir das ações que provocaram a salinização do baixo São Francisco e aos desdobramentos dela decorrentes, e, a partir de suas reflexões, fortalecer o chamado que tem se realizado para os olhares e as pesquisas geográficas sobre a temática discutida. Não encerra, mas contribui para uma longa e complexa discussão que envolve o econômico, o social, o cultural, as tradições, os interesses, o privado, os agentes, o coletivo, os usos e os abusos relacionados à produção do espaço em torno do São Francisco. É justamente a importância destes recursos hídricos para as vidas que deles dependem e as decisões políticas que giram em torno deles que tornam as discussões sobre as questões relativas à salinização do baixo São Francisco de extrema necessidade às investigações científicas que buscam envolver em suas análises os aspectos físicos e sociais, de modo a considera-los integrantes de uma totalidade espacial mais complexa.

\section{REFERÊNCIAS}

ARAÚJO, S. S. de; AGUIAR NETTO, A. O. ; GOMES, L. J. A percepção ambiental, identidade e pertencimento dos moradores do povoado Cabeço, em Brejo Grande/SE, frente às inundações na foz do rio São Francisco. Desenvolvimento e Meio Ambiente (UFPR), v. 36, p. 239-253, 2016.

BESSE, Jean-Marc. El espacio del paisaje. III JORNADAS del Doctorado em Geografia. Desafíos Teóricos y Compromiso Social em la Argentina de Hoy, La Plata, Faculdad de Humanidades y Ciencias de la Educación. Universidad Nacional de La Plata, septiembre de 2010.

Estudos Geográficos, Rio Claro, 17(1): 32-42, jan./jun. 2019 (ISSN 1678-698X) http://www.periodicos.rc.biblioteca.unesp.br/index.php/estgeo 
BRASIL. Ministério da Integração Nacional. Programa de Monitoramento da Cunha Salina, 2005.

CRUZ, Elizabeth Ferreira. A problemática para a água no mundo: desafios para a luta feminista. In: ARANTES, Rivane; GUEDES, Vera (orgs.). Mulheres, trabalho e justiça socioambiental. Recife: SOS CORPO. Instituto Feminista Para a Democracia, 2010.

FONTES, L.C.S. O rio São Francisco após as grandes barragens - Mudanças recentes no regime hidrossedimentólogico e na dinâmica fluvial do baixo curso. In: LUCAS, A. A. T.; AGUIAR NETTO, A. O. (Orgs.). Águas do São Francisco. São Cristóvão: UFS, 2011, p. 33-68.

ROSSI, Marina. A seca no São Francisco que salga o café e adoece moradores em uma cidade de Alagoas. 6 de novembro de 2017. Disponível em: https://brasil.elpais.com/brasi/2017/11/02/politica/1509640183 248220.html. Acesso em: 19 de dez de 2017.

SANTOS, Milton. O retorno do território. In: SANTOS, Milton; SOUZA; Maria Adélia A. de; SILVEIRA, Maria Laura (Orgs). Território, Globalização e Fragmentação. São Paulo: Hucitec, 1994.

SANTOS, Milton; SILVEIRA, Maria Laura. O Brasil: território e sociedade no início do século XXI. Livro Vira-Vira 1. Rio de Janeiro: BestBolso, 2011.

SAUER, Carl. Morfologia da Paisagem. In: CORRÊA, Roberto Lobato; ROSENDAHL, Zeny (Orgs.). Paisagem, tempo e cultura. Rio de Janeiro: EDUERJ, 1998.

SOUZA, Rodolfo Marcelo Gonçalves. Caracterização hidrodinâmica e estimativa do transporte de sal no estuário do Rio São Francisco. 2015. Dissertação (Mestrado em Meteorologia). Instituto de Ciências Atmosféricas. Universidade Federal de Alagoas, Alagoas.

TUAN, Yi-Fu. Espaço e Lugar: a perspectiva da experiência. São Paulo: DIFEL, 1983.

UNGER, Nancy Mangabeira. Da Foz à nascente: o recado do rio. São Paulo, Cortez; Campinas, SP: Editora da Unicamp, 2001. 